\title{
La mirada interactiva. \\ De la gráfica de la interacción impresa a la edición de contenidos
}

\author{
Interactive Look. \\ From the graphics of printed interaction to the \\ graphics of digital interaction
}

Eugenio Vega Pindado

(Universidad Complutense de Madrid)

Fecha de recepción: 13 de enero de 2014

Fecha de revisión: 18 de enero de 2014

Para citar este artículo: Vega Pindado, E. (2014): La mirada interactiva.

De la gráfica de la interacción impresa a la edición de contenidos, Icono 14, volumen (12), pp. 187-218. doi: 10.7195/ri14.v12i1.655 


\section{Resumen}

Los medios digitales han sustituido progresivamente al papel como soporte de comunicación. Han hecho necesaria la existencia de dispositivos mecánicos para la lectura del los documentos que antes eran directamente manipulados por el lector. En el papel la disposición gráfica de textos e imágenes dependía de cada libro. La elección del tamaño, del formato y del color se hacía en función de la estructura de la obra. Sin embargo, en la era digital, la disposición gráfica depende del dispositivo que pone a disposición del lector los documentos. A pesar de sus ventajas evidentes para reordenar la información, han incorporado procedimientos interactivos de los medios impresos que guardaban relación con la habilidad del lector para mirar, leer y comprender la composición. Este trabajo analiza la pervivencia de los modelos gráficos de la interacción impresa en estos nuevos soportes.

\section{Palabras clave}

Interacción - Comunicación gráfica - Tipografía - Libro - Ebook - Lectura

\section{Abstract}

Digital media has gradually replaced paper as a medium of communication. These new media have need the existence of mechanical devices for reading documents that until now were directly manipulated by the reader. In printed paper graphical layout of text and images depended on each book. The choice of size, color and proportion was a consequence of the structure of the work. However, in digital age, graphic layout depends on the device that makes available documents to the reader. Despite its obvious advantages to reorder the information, have incorporated interactive procedures from print media that were relevant to the reader's ability to see, read and understand the whole layout. This paper analyzes the survival of graphical interaction models in these new media.

\section{Key Words}

Interaction - Graphic communication - Typography - Book - Ebook - Reading 


\section{Introducción}

La proliferación de dispositivos electrónicos para la lectura de documentos, hasta hace poco sólo disponibles en papel, ha puesto de relieve la importancia de la interacción en los procesos comunicativos.

Pero esta no es una cualidad exclusiva de los soportes digitales; ha estado presente en la comunicación gráfica incluso antes de la aparición de la imprenta. El libro, con sus páginas numeradas y su organización en apartados, fue concebido para permitir al lector que decidiera el orden en que quería leer. El diseño gráfico desarrolló procedimientos muy variados para organizar las páginas de forma que propiciaran una disposición armónica y una interacción razonable. El papel fue también escenario para la experimentación formal; las ideas estéticas influyeron en la organización del impreso tanto o más que las necesidades funcionales.

Esa interacción del soporte escrito o impreso era de una naturaleza y dimensión diferente a la de los medios digitales. La interacción digital no sólo anima al lector a leer en el orden que desee sino que le permite organizar los contenidos en una disposición de acuerdo a sus gustos y necesidades; puede incluso comentarlos, editarlos y distribuirlos a través de las redes sociales y dotarles de un sentido no siempre coincidente con el que originalmente pudiera tener. Este es el aspecto más relevante al que ha debido enfrentarse el diseño gráfico en estas nuevas formas de edición.

El objetivo principal de este trabajo es comprender la interacción del diseño gráfico en el soporte impreso y señalar su influencia en las nuevas formas de la cultura digital. De qué forma, la tipografía y el diseño gráfico tradicional establecieron lenguajes y procedimientos de interacción que siguen presentes en el proceso comunicativo a pesar de las innovaciones tecnológicas.

\subsection{Interacción en la comunicación impresa}

La interacción es una acción recíproca entre dos o más personas, objetos o agentes que permite el intercambio de información mediante técnicas de registro, la 
primera de las cuales fue la escritura; toda forma de comunicación supone un intercambio de información entre emisor y receptor. Y esto ha sido así desde mucho antes que los ordenadores transformaran la comunicación visual y proporcionaron instrumentos para la edición y la difusión de contenidos.

Sin duda, imágenes gráficas tradicionales como los carteles y las señales proporcionan una interacción limitada en comparación con las actuales formas de intercambio comunicativo. Sus mensajes provocaban reacciones comunicativas y eran motivo de valoración estética, pero no fueron concebidos para ser manipulados sino tan sólo para ser vistos y leídos. Los libros, en cambio, eran objetos manipulables, estructuralmente más complejos porque necesitaban de la iniciativa del lector y para su producción era necesaria una compleja tecnología. Por otra parte, suponían necesariamente un proceso narrativo, secuencial, que podía incluir imágenes y textos con varios niveles de información: páginas que se suceden unas a otras, notas que amplían el texto principal, pies de imágenes que pueden leerse antes 0 después, gráficos y mapas que proponen órdenes de lectura particulares.

Incluso algunos libros se concibieron expresamente para ser leídos de forma no lineal. Un diccionario es tan interactivo que nunca será posible que dos lectores puedan leerlo siguiendo un mismo orden. Así sucedía con la propia Biblia, organizada en páginas y numerados sus versículos para facilitar el acceso inmediato, un libro que difícilmente se leía de principio a fin.

\subsection{Lenguaje gráfico y comunicación}

El diseño gráfico se encarga de dar forma a los contenidos para que el lector pueda interactuar con ellos. Codifica visualmente un mensaje de forma comprensible para un receptor o destinatario. Desde que comenzara a usarse la expresión diseño gráfico en los años veinte del pasado siglo, esta actividad ha cambiado tanto que aquella primera definición no parece suficiente para explicar su actual amplitud y diversidad. Con su particular utilización del lenguaje gráfico, la televisión primero y los ordenadores después, han puesto en discusión aspectos decisivos de la práctica gráfica que parecían consolidados por una tradición de siglos.

ICONO14 | Año 2014 Volumen 12 N 1 | ISSN: 1697-8293 | DOI: ri14.v12i1.655 
Esta circunstancia estuvo en el origen de la sustitución progresiva, aunque no definitiva, de la expresión "diseño gráfico" por "comunicación visual" que se consideraba más adecuada a la complejidad de la práctica del diseño. Ya en 1956 tal denominación fue usada en la Hochschule für Gestaltung de Ulm con la creación de un departamento que llevara ese nombre y donde la formación se repartía en dos áreas esenciales: tipografía y cinematografía. (Spitz, 2012; Rinker, 2007).

El diseño siempre tuvo por objeto la transmisión de contenidos persuasivos, informativos y formativos a través de un soporte bidimensional mediante la combinación de tipografía, ilustración y fotografía en una composición reglada y ordenada que orientaba la lectura y permitía la comprensión.

La gráfica se ocupaba, por tanto, de dar cuerpo al mensaje mediante la organización espacial del soporte y el tamaño y la posición de los elementos disponibles. Hasta hace poco más de medio siglo fue una actividad exclusivamente bidimensional y silenciosa que expresaba la temporalidad mediante recursos compositivos de carácter plástico, de forma muy similar a cómo lo resolvían la pintura y otras formas de expresión artística. La imagen era única y fija, la secuencialidad aparecía mediante artificios bidimensionales relacionados con aquella tradición pictórica. Para captar la atención del lector y establecer una jerarquía informativa se asignaban características morfológicas adecuadas a cada componente. El tamaño, el color, la posición y la forma de cada componente visual atraen, en mayor o menor medida, la atención del espectador. No había otra alternativa porque lo que estaba en un papel no podía moverse. (Vega, 2004)

La imagen cinética es extraña al diseño gráfico porque no es posible la sucesión temporal de imágenes que caracteriza al lenguaje audiovisual. En el cine, en la televisión, la apariencia de movimiento se produce gracias a que transcurre tiempo en la contemplación de cada cuadro, tiempo que conforma y estructura la narración.

Desde la perspectiva pictórica que la tipografía comparte, el movimiento no puede materializarse sino de forma indirecta mediante la tensión, el equilibrio y la distancia entre las formas en la propia composición impresa. Un cambio de 
cualquiera de sus partes, obliga a las demás a reubicarse para garantizar una organización armónica que facilite la comprensión y la lectura. La comunicación gráfica crea imágenes con elementos formales, a la manera en que los pintores componían sus cuadros con imágenes fijas, en composiciones que no admitían modificación.

La elección del cuerpo, de la interlínea, de la prosa y otras decisiones similares llevaban al ajuste detallado de cada cosa en el marco de la página, ajuste que se consideraba imprescindible para la buena forma del impreso, exigencias más ligadas al oficio y a la tradición que a una verdadera necesidad comunicativa.

\subsection{Expresión gráfica frente a interacción}

La gráfica impresa, como toda forma de expresión comunicativa, no pretende tan sólo hacer llegar un mensaje por medio de una adecuada interacción (Gamonal, 2011). También quiere expresar significados que tienen que ver con el contexto social y cultural en que se difunde y se ve influida por las corrientes estéticas que penetran en el diseño con intensidad similar a como lo hacen en las manifestaciones artísticas convencionales.

En su "Teoría de la clase ociosa" Thorstein Veblen critica a William Morris (Veblen, 2004) con una vehemencia inusitada. Señala que los libros de Kelmscott Press no eran otra cosa que objetos inútiles, incapaces de transmitir información y cuyo verdadero sentido no era otro que expresar la riqueza de quien lo poseía. Veblen explicaba:

"Como esos productos requieren el trabajo a mano, son más costosos; son también de uso menos cómodo que los libros elaborados con vistas únicamente a su utilidad; por consiguiente, constituyen una demostración de la capacidad del comprador para gastar sin tasa, a la vez que para derrochar tiempo y esfuerzo.

La Kelmscott Press redujo la cuestión al absurdo -mirada sólo desde el punto de vista de la utilidad bruta- al imprimir libros para uso moderno editados con tipografía anticuada, impresos en letra gótica y encua- 
dernados en vitela cosida con correas. Como característica ulterior que determina el papel económico de los libros artísticos, tenemos el hecho de que, en su mejor forma, esos libros más elegantes sólo se imprimen en ediciones limitadas. Así, una edición limitada es una garantía -un tanto tosca, es cierto- de que ese libro es escaso y, por ende, costoso, $y$ una distinción pecuniaria a su consumidor."

Veblen añade que nada tenían que ver las técnicas empleadas por Morris, ya desfasadas en 1895, con las innovaciones tecnológicas de los periódicos y los libros más corrientes de su tiempo. No preocupaba a Morris la organización del contenido sino la composición formal y los materiales.

Que los libros de Morris eran un anacrónico objeto de lujo era algo evidente ya en su propia época, cuando los impresores comerciales estaban más preocupados en reproducir fotografías e imprimir en color que en recuperar las técnicas de impresión del siglo XV (Ivins, 1975). Morris no estaba interesado en facilitar la comprensión del libro, no era su prioridad. No quería ningún tipo de interacción, tan sólo esperaba del lector que contemplara una expresión gráfica cuyo objetivo esencial como editor era, según propia confesión, alcanzar la belleza tipográfica de la Hypnerotomachia Polliphili de Aldo Manuzio (Blackwell, 1992).

El libro entendido como objeto, apreciado por sus cualidades formales ajenas al contenido, ha sido una constante en la actividad editorial. Y para ello no han necesitado emplear anticuadas técnicas artesanales porque tal cosa no tiene que ver con la actualidad de los procedimientos sino con el desdén por la información materializada en el impreso. Libros cuyo contenido es su mismo diseño han existido siempre: A Designer's Art de Paul Rand; Raster Systeme de Josef Müller Brockmann; Schiff nach Europa de Kart Gestnert y Markus Kutter; The End of Print de David Carson o la serie Best Verzorgde Boeken de Irma Boom. Son tan sólo una reducidísima muestra de entre muchos (Hochuli, 1993). Su influencia sobre el diseño editorial ha sido mayor que su repercusión comercial y cultural.

La interacción irrita a los diseñadores. El diseñador quiere del lector un determinado comportamiento aunque nunca ha podido evitar que el usuario mire el

DOI: ri14.v12i1.655 | ISSN: 1697-8293 | Año 2014 Volumen 12 Nº 1 | ICONO14 
impreso cómo le parezca, fijándose en algo irrelevante y desdeñando aspectos más decisivos de la composición gráfica. Pero, en todo caso, el lector, por mucho que quiera, no puede modificar la gráfica. El diseño era inalterable una vez que el libro había sido impreso y la forma de la página y, por extensión del libro, era el resultado de una "buena forma" que no debía ser cambiada (Bill, 1947)

La comunicación visual sigue prestándose a un proceso contemplativo, a una exhibición que provoca entusiasmo o desaprobación al margen de su mensaje y que se rige por criterios estéticos. A esta visión ha contribuido el análisis formalista que ha ocupado a la historiografía del diseño (Drucker, 2009) que quiere explicar las imágenes como obras de arte más o menos expresivas antes que como soportes para la información o la persuasión. Pero un énfasis en el tratamiento poético de la tipografía y de la composición, hasta el punto de ser objeto de atención por el destinatario, puede tener como consecuencia una pérdida de la capacidad comunicativa. "Nuestra conciencia del medio utilizado para transmitir un mensaje distrae nuestra atención del mensaje en si» como sucede con las disposiciones excesivamente complejas" (West, 1993).

\subsection{La mirada del lector}

Para que la interacción sea efectiva, es necesario iniciarse en la complejidad del lenguaje gráfico y adquirir suficiente destreza para ordenar y reordenar el contenido. No se pretende en este punto indagar sobre la compleja relación entre quien el lector y sus lecturas, en el papel que el contexto juega en la interpretación de lo leído. (Eco, 1993) El propósito es aquí más sencillo.

Previamente a cualquier interpretación, la mirada explora la página en busca de aquellos elementos gráficos que puedan proporcionar información. Quien lee no es consciente del complejo proceso que supone la organización del libro, desconoce no sólo la tecnología sino las razones y sinrazones que han llevado a la formación de la tradición tipográfica. Durante décadas se ha intentado educar al profano en los principios esenciales de la gráfica con la intención de que pudiera asimilar los criterios con que los diseñadores profesionales concebían su tarea (Morison, 1936). De esta forma podrían comprender mejor el lenguaje gráfico que empleaban

ICONO14 | Año 2014 Volumen $12 N^{\circ} 1$ | ISSN: 1697-8293 | DOI: ri14.v12i1.655 
y quizá también aplicarlos a los productos comunicativos que fueran capaces de llevar a cabo. Esta educación le sería útil para producir, si lo necesita, sus propios documentos, algo que desde hace décadas la tecnología digital ha convertido en una realidad.

En su obra más famosa, "die neue Typographie", Jan Tschichold insistía en esta obligada disposición: "Es necesaria una explicación de los principios espirituales de la nueva tipografía para todo aquel que quiera triunfar en el campo del impreso".

Pero sabido es que Tschichold renegó de su actividad vanguardista a partir de 1993 (Burke, 2007) y dedicó mucha energía a defender los principios de la composición tradicional con la misma convicción que propagara las ideas de la nueva tipografía en los años veinte. En 1949 publicó en Basilea un pequeño manual, “Was jedermann vom Buchdruck wissen sollte", cuyo titulo hacía referencia a todo aquello que cualquiera debería saber sobre tipografía y producción gráfica. La modesta intención quedaba clara en sus primeras páginas: “Este librito está dirigido a empresarios, a empleados de grandes empresas, anunciantes potenciales, productores de materiales impresos, coleccionistas de libros, estudiantes gráficos, escritores y cualquiera persona interesada".

Y añade que esa obra "no va más allá de ser una guía para ordenar materiales impresos", actividad para la que no estarían de más esos conocimientos esenciales. En sus poco más de setenta páginas Tschichold explica al hombre corriente aspectos relacionados con los sistemas de impresión, la calidad del papel, las técnicas de composición y "la buena y mala tipografía".

Se extiende Tschichold en diversas consideraciones que ya había expresado en otros libros más extensos e insiste en sus ideas acerca del orden y la claridad como ejes principales de la buena forma tipográfica, sintetizadas aquí para el lector no iniciado. Y como era su costumbre, Tschichold anteponía el orden a cualquier otra cosa, expresaba una serie de ideas estéticas que estaban ligadas a la tradición por encima de las consideraciones funcionales. El lector era considerado un sujeto pasivo que leía siempre a una misma distancia, que percibía de una forma previsible los contenidos y que era poco amigo de fantasías. La letra alcanzaba su principal 
virtud al volverse invisible. Orden y simplicidad formaban parte de la forma de pensar de Tschichold tanto en su etapa vanguardista como en su retorno al clasicismo a partir de 1933.

En “Was jedermann vom Buchdruck wissen sollte" insiste en lo que para él son esos principios esenciales: "La buena tipografía es clara, ordenada y hermosa; la mala es desordenada, sucia y se ve fea". Pero no explica los criterios que establecen esas categorías que no pueden reducirse a meras fórmulas. Las normas académicas sobre la organización del impreso, construidas en principio sobre una supuesta funcionalidad comunicativa, propugnaban la disposición en bloques anodinos y regulares que proporcionasen un gris uniforme a la página (Müller Brockmann, 1960). El tratamiento tipográfico establecía un orden para conocer la relevancia de cada apartado del texto.

En la composición clásica que sobrevivió a las vanguardias, el texto no dejaba de ser un río que fluía a través de un único canal: las líneas de cada página y las páginas de cada libro. Un flujo incapaz de admitir otro orden de lectura. La interacción quedaba limitada al ritmo y la velocidad con que el destinatario afrontase la lectura de ese flujo.

Son muchas las tradiciones tipográficas que sin una sólida base para su defensa, han llegado a nuestros días eludiendo un necesario debate (Martínez de Sousa, 1994; Marín Álvarez, 2013). El rechazo a las líneas cortas en la composición tipográfica, una de las constantes del diseño editorial, no se apoya en ninguna razón funcional. Las líneas cortas, las viudas o huérfanas no dificultan la lectura, como ha demostrado la práctica reciente en las muchas composiciones descuidadas para el impreso y en el libro electrónico. No pasan de ser signos de cultura tipográfica.

La distribución de los blancos en la página responde más a razones estéticas y suele dificultar la lectura cuando los sistemas de encuadernación impiden abrir el libro con libertad y las masas de texto carecen de un margen interior suficiente. Stanley Morison (1936) defendía el respeto a la tradición tipográfica en un lenguaje en el que eran frecuentes argumentos ideológicos antes que funcionales. 
"Pero la tradición es algo más que el embalsamamiento ceremonial de formas que se han dejado a un lado tiempo atrás. La suma de experiencias acumuladas en un periodo de tiempo de duración mayor que la vida de un hombre, y unificadas por las sucesivas generaciones, no debe descartarse así como así. Por lo tanto, tradición es otra forma de decir unanimidad sobre principios básicos contrastados por el juicio, los errores y las correcciones de muchos siglos".

El diseño establece una composición fija en el soporte. El lector sólo puede interactuar modificando el orden de lectura y la intensidad con la que el sistema perceptivo atiende a cada elemento. Esa alteración de la mirada es tan intensa como quiera y puede actuar caprichosamente. Del mismo modo que el espectador de televisión recompone la programación a partir de los fragmentos que le proporciona el zapping (Martínez Requena, 1996). La mirada interactiva capacita al lector para recomponer mentalmente un contenido dado, en cierta manera, crea algo nuevo con material ya existente.

La complejidad de lo que sea objeto de la comunicación determina la variedad interactiva. Aquellos libros cuyo contenido está en el texto, como las novelas, serán motivo de una organización compositiva lineal. El libro en forma de códice fue inventado para su manipulación, pero la interacción gráfica es esencialmente fruto de la observación. No podía ser de otro modo.

Puede afirmarse que en esa manipulación conviven dos formas de interacción:

1. Una interacción de carácter secuencial a partir de la organización del libro en páginas ordenadas en un único sentido. El espectador podía alterar ese orden y asignar un tiempo diferente para cada apartado. Podía manosear el papel, podía doblar las páginas, en definitiva, interactuaba con un objeto físico.

2. Otra interacción de carácter formal que tiene lugar mediante la observación activa de cada doble página, de intensidad diferente según el modelo de disposición formal a que se enfrentara. Cuando el contenido propiciaba una 
disposición meramente lineal poco más podía hacer que no fuera leer el libro del revés y renunciar a su comprensión. Pero cuando la composición permitía la convivencia de diversos elementos gráficos, el lector era animado a reordenar perceptivamente lo que tenía ante sí para comprender el sentido. En cualquier caso, por mucho empeño que pusiera, no podía modificar ni la forma ni el mensaje de la página impresa. No cabía que la disposición fuera otra que la decidida por el diseñador. Lógicamente podía romper las páginas y reordenarlas a su antojo pero de tal atrevimiento difícilmente podía resultar algo comprensible. No sería más que una actitud de rechazo a la decisión del diseñador sobre la composición gráfica.

\subsection{La gráfica en la interacción digital}

En la sociedad de consumo de la era industrial el destinatario no tenía otra opción que ponerse delante de la pantalla para consumir lo que emitían las grandes empresas de comunicación; podía elegir uno u otro canal o apagar el receptor, pero no podía interactuar porque la estructura audiovisual no permitía ni siquiera la mirada interactiva que inventó el libro.

El lenguaje audiovisual era ajeno a la interacción. No cabía un orden distinto al que el creador hubiera fijado para un determinado tiempo. Cualquier alteración de ese orden negaba la comprensión del contenido porque la obra no había sido concebida para ser vista de un modo diferente.

La tecnología digital propiciaría otras formas de comunicación no lineal. Los ordenadores cambiaron la comunicación y la cultura pero Internet tardó más de treinta años en ejercer alguna influencia significativa en la vida de las gentes hasta que a mediados de los años noventa tuvo lugar la irrupción de las empresas comerciales en la red (Castells, 2000). Como sucedió con la imprenta en el siglo $\mathrm{XV}$ y con la televisión en el siglo XX no fue la aparición de la tecnología lo que cambió la vida, sino su transformación en un soporte para la información, el entretenimiento y el aprendizaje accesible a un gran número de usuarios. Convirtió al consumidor tradicional en un nuevo tipo de "consumidor creador" que ha devenido en eje central de estas nuevas relaciones (Moggridge, 2010).

ICONO14 | Año 2014 Volumen $12 N^{\circ} 1$ | ISSN: 1697-8293 | DOI: ri14.v12i1.655 
En este nuevo tiempo no bastaría la contemplación, única interacción posible con la radio y la televisión. No se puede mirar Google de la misma forma que se mira o escucha la BBC porque Google no hace nada si el usuario no toma la iniciativa. Y lo mismo sucede con otras tantas experiencias interactivas. Incluso en las versiones digitales de los diarios es necesario que el usuario "haga" algo, para que pueda "consumir" sus "páginas". La posibilidad de comentar los contenidos, seleccionar parte de ellos y enviar esos comentarios a otros usuarios, es una forma de edición que nunca fue posible con los medios impresos (Arroyo y Baños, 2011).

Gracias a los primeros ordenadores el espectador adquirió experiencia en editar documentos mediante procesadores de textos y otras aplicaciones informáticas que eran las mismas que se utilizaban con fines profesionales. Esta educación resultaría imprescindible para manipular los contenidos, reordenarlos y hacerlos propios.

Con intención parecida a la que en otro tiempo tuviera Jan Tschichold, Erik Spiekermann escribió en 1993 su "Stop, Stealing Sheeps, and Find Out how Type Works", uno de los primeros manuales tipográficos en la era digital (Spiekermann, 1993). Cuando los usuarios comenzaron a producir material impreso, se familiarizaron con nociones hasta entonces desconocidas para el gran público. Cuerpo, interlínea, sangría o kerning empezaron a ser familiares porque cada día, más y más personas confeccionaban documentos para uso privado pero también público sin más conocimiento gráfico que el derivado del uso de los procesadores de textos y de otras aplicaciones informáticas. Spiekermann era consciente de que el manejo directo de las aplicaciones digitales daba un sentido nuevo al ajuste tipográfico. Los ordenadores permitieron a cualquier usuario disponer de un sistema de composición e impresión que ponía en sus manos los recursos técnicos que hasta hacía poco estaban reservados a la industria.

\subsection{Manipulación, orden y sentido}

El diseño interactivo no sólo permite que el lector mire como quiera el mensaje sino que le anima a recomponerlos modificando la relevancia gráfica de cada una de sus partes. Mientras el impreso solamente se dejaba observar, los soportes digitales admiten que el lector disponga sus contenidos en un orden diferente al

DOI: ri14.v12i1.655 | ISSN: 1697-8293 | Año 2014 Volumen 12 Nº 1 | ICONO14 
inicialmente ideado. Y aunque no se manipule el contenido, es posible que tal reorganización destruya la intención comunicativa que inicialmente hubiera tenido.

No es extraño que los lectores puedan leer sin problemas cuando son ellos mismos quienes alteran la disposición de los textos olvidando todas las normas que la tipografía estableció durante siglos. Y esto no ha sucedido sólo desde que los ebook permiten modificar todos los ajustes tipográficos.

La práctica demuestra que la gente puede leer en pésimas condiciones. Los alemanes fueron capaces de hacerlo sin grandes problemas aunque sus periódicos estuvieran compuestos en Fraktur y otras variantes góticas (Kinross, 1992). Durante décadas los diarios alemanes utilizaban lo que se tenía por una escritura nacional, en cuerpos pequeños y en una disposición no siempre cuidada. Tal cosa no impidió que los diarios alcanzaran durante el periodo de Weimar unas tiradas muy elevadas y tan sólo comenzarían a abandonar esa escritura al final de la Segunda Guerra Mundial (Burke, 2007).

La composición gráfica comenzó a ser compartida con los usuarios cuando el progreso técnico proporcionó instrumentos accesibles. En la medida que el destinatario se convertía en editor, se acostumbraba a manejar el lenguaje de la forma que creía más eficaz. Y seguía todo tipo de modelos para decidir sus opciones: modelos académicos, populares, de propia invención y cualquier mezcla de todos ellos.

Los motivos por los que un usuario modifica la disposición gráfica pueden ser de índole diversa:

1. En primer lugar, estos cambios pueden estar causados por razones prácticas: un tamaño de letra más grande es, en la mayoría de los casos, más fácil de leer; y del mismo modo, un contraste más intenso contribuye a una mejor percepción. La usabilidad se refiere a la capacidad de un software de ser comprendido, aprendido, usado por el usuario, en condiciones específicas. Nadie discute que los dispositivos electrónicos permitan modificar las condiciones de lectura para obtener una mejor "experiencia de usuario" aunque ello suponga una ruptura con las normas tipográficas que velan por el orden y la armonía. 
La expresión "experiencia de usuario" comenzó a ser usada a mediados de los años noventa (Norman, 1995), para referirse un diseño centrado en el usuario y no en la tecnología. Que superase la vieja idea de que era posible determinar las necesidades de los consumidores, en función de factores psicofísicos y sociológicos que eran susceptibles de medida y valoración. Este concepto está relacionado con la facilidad con que se utiliza un objeto manufacturado o un servicio para un propósito concreto, pero también se refiere a los principios que determinan la percepción de la eficacia de ese producto y simplifican su uso. En cierta medida, la expresión usabilidad ha venido a sustituir al viejo concepto de funcionalidad que era corriente en la literatura sobre diseño.

2. Pero los cambios en la organización de los documentos electrónicos también guardan relación con la necesidad de personalizar aquello que se considera propio sin que tales modificaciones supongan ninguna mejora funcional. Desde siempre los consumidores han necesitado sentirse diferentes. Desde el siglo XIX la industria hizo un esfuerzo para ofrecer opciones con significados que sirvieran a los compradores para expresar sus inclinaciones personales (Forty, 1986) o, lo que era más relevante, su posición social. Ciertos utensilios de uso personal fueron personalizadas para atraer a los potenciales compradores sin cambios apreciables en su funcionalidad. Los productos servían para expresar la relación de los consumidores con la escala social sin preocuparse de ventaja técnica de ningún tipo.

En su noción de experiencia de usuario, Donald Norman hacía suya la idea de que la relación de las personas con los objetos y con las aplicaciones depende de aspectos emocionales que tienen que ver con el significado de las formas, con las experiencias particulares, con el carácter, y, en definitiva, con la cultura. La predisposición hacía algo tiene su causa en la experiencia, en las expectativas de cada individuo así como en el marco cultural de la sociedad en la que vive.

Se ha insistido antes en la idea de que la interacción irrita al diseñador. La tradición estableció que las reglas del diseño gráfico tenían por objeto formalizar la interacción en una imagen fija, en una forma estática, no sujeta a cambios. Y menos aún se

DOI: ri14.v12i1.655 | ISSN: 1697-8293 | Año 2014 Volumen 12 Nº 1 | ICONO14 
entendía que tales modificaciones pudieran ser capricho de lectores sin la necesaria cultura gráfica por mucha formación que tuvieran en otra disciplina. Un pintor no podría comprender que el comprador de su obra pudiera alterar la composición de uno de sus cuadros. Tampoco un escritor querría que cambiaran su texto, pero con seguridad le resultará indiferente que lo compongan en Garamond o en Univers. Sin embargo, en un sistema interactivo el lector puede reordenar los elementos gráficos, activar opciones que destruyan el orden y la armonía que fijó el diseñador para conseguir unas mejores condiciones de lectura y comprensión. Los distintos elementos gráficos (tipografía, color, tamaño, posición y orden) pueden ser alterados de forma separada y darían lugar, por tanto, a un infinito número de combinaciones. Pero desde la perspectiva gráfica, sólo alguna sería correcta, sólo alguna restituiría el orden y la armonía, el sentido "gráfico" que hace comprensible la comunicación en la idea tradicional del diseño.

Jan Tschichold dejó muestras de su convicción de que el detalle tipográfico era imprescindible, fue exigente hasta extremos injustificados en esa insistencia. Pueden verse sus anotaciones (McLean, 1975) en las que exigía la corrección del espaciado, la interlínea y cualquier otro detalle de la composición tipográfica para obtener un resultado mejor. Esta constante obsesión por el detalle generó tensiones durante sus años en Penguin (Baines, 2005) y contribuyó a la imagen de exigencia le acompañó hasta sus últimos años. Lo que no está claro es si toda aquella cabezonería era necesaria para la lectura o tan sólo era un asunto relacionado con la estética del impreso, asunto del que Tschichold hizo el centro de sus reflexiones.

Las normas tipográficas, que han devenido en un conjunto de reglas no siempre razonadas, no son imprescindibles para la comprensión del mensaje. El usuario modifica los contenidos y utiliza normas de organización gráfica no académicas. Valora aspectos comunicativos al margen del orden y la armonía de la tradición para tomar esas decisiones. Si tan decisivas fueran todos esos ajustes para la lectura, ¿cómo es posible que los sistemas electrónicos dejen al buen criterio del lector el ajuste de esos parámetros? A poco que el usuario cambiara cualquier cosa, el documento perdería sus cualidades comunicativas, dejará de ser comprensible, ni siquiera legible. Ante la dificultad, el observador hace un mayor esfuerzo, modifica sus hábitos de lectura, dedica algo más de tiempo a la compleja actividad de la lectura pero supera con éxito la prueba. 
La amplia variedad de soportes electrónicos para la difusión de documentos hace muy difícil normalizar la producción gráfica. El ordenador, el ebook, la tableta, el smartphone y otros dispositivos híbridos presentan condiciones de almacenamiento y lectura diferentes. Las relaciones formales de los elementos gráficos no pueden mantenerse en todos los soportes y en muchas ocasiones los cambios afectan al sentido.

En la gráfica impresa la elección de una categoría de interacción dependía del contenido. Si un libro precisaba mayor flexibilidad, empleaba más de una columna en un formato quizá más ancho, elegía distintos niveles tipográficos y optaba por un tamaño de página algo mayor que permitiera una adecuada distribución. Un lector podía manejar cualquier tipo de libro al margen de su encuadernación, su tamaño, papel o número de tintas. El medio con el que el usuario se relacionaba con el contenido era el propio libro una vez impreso: contenido y continente eran inseparables, eran la misma cosa.

En los nuevos soportes esto es diferente. Todos los libros contenidos en un Kindle, sea cual sea su contenido y su estructura, se muestran con la misma tipografía y en una página del mismo tamaño.

Los libros electrónicos no pueden abordar todas estas características especializadas, no pueden competir con la capacidad que la web tiene para actualizarse tecnológicamente e implementar toda suerte de interacción. Son dispositivos no programables que progresan mucho más lentamente porque fueron concebidos para un uso muy concreto.

Los documentos han de adaptarse a cada soporte para que puedan ser leídos por los usuarios. Si en el impreso contenido y continentes eran inseparables, en la interacción digital un mismo contenido puede ser consumido en cualquier dispositivo, sean cuales sean sus características técnicas. El contenido es único pero su forma, su disposición, es múltiple, tan diversa como numerosos sean los dispositivos que puedan distribuir el documento. El contenido debe modificar su disposición gráfica según sea la resolución del dispositivo de salida, su formato, el número de colores y los mecanismos para la interacción: ratón, cursor, teclado, pantalla táctil, voz humana. 
La reordenación gráfica de los documentos puede afectar a su sentido. La interacción digital permite al espectador modificar la visualización conforme a sus condiciones perceptivas y a sus intereses. $Y$ esta previsto que esos cambios puedan producirse sin destruir los componentes que constituyen su contenido.

El documento ha sido concebido para que su comprensión no dependa de una composición fija, es un flujo de información ajeno a una disposición gráfica determinada y que pueda adquirir formas muy dispares. En Internet, la tecnología adapta la información a un soporte multimedia concreto. Un periódico presenta una disposición distinta si se accede a su versión digital desde un teléfono o desde un ordenador convencional. El texto es el mismo, las imágenes también, pero no es seguro que el resultado informativo lo siga siendo porque las relaciones visuales que son posibles en la pantalla horizontal de un ordenador, no lo son en la más pequeña de un smartphone. Si las relaciones entre los componentes del sistema gráfico son importantes en la creación del sentido, los cambios en su disposición afectarán al significado.

Los modelos de interacción para la gráfica impresa han perdido parte de su vigencia porque el diseño gráfico no tiene el control sobre la disposición final de los documentos. Las nuevas técnicas en la producción gráfica para los nuevos soportes se caracterizan por una creciente interactividad que permite al usuario, al lector, ordenar y modificar la organización de los contenidos, su edición y reenvío. Este aspecto de los nuevos medios hace difícil que la tradicional forma de diseño gráfico, basada en el control total de la composición por parte del diseñador pueda seguir perviviendo en el nuevo universo multimedia.

La función del diseño gráfico no es ya organizar la forma de la información sino organizar el flujo de la información al margen de los dispositivos que lo vehiculan. Si la actividad del diseñador gráfico tenía como rasgo característico la disposición gráfica en el papel impreso, cabe preguntarse cuál es su función en la interacción digital. Su función sigue siendo organizar el contenido para facilitar la interacción de un usuario capaz de alterar la disposición de los elementos que componen el conjunto comunicativo. Y teniendo en cuenta la tecnología y las circunstancias del proceso. No es muy diferente de lo que hacía con los libros.

ICONO14 | Año 2014 Volumen $12 N^{\circ} 1$ | ISSN: 1697-8293 | DOl: ri14.v12i1.655 


\section{Material y Métodos}

Para alcanzar los objetivos de este trabajo se contextualiza el tema de estudio mediante la bibliografía y la documentación relevante que permiten establecer la necesaria orientación para el análisis.

Tras una descripción del diseño en la comunicación visual impresa y de las características de la interacción gráfica, se describen y analizan aquellas formas de diseño condicionadas por la interacción digital. Se quiere establecer una categorización de las formas esenciales de interacción gráfica en el soporte impreso y su relación con nuevas formas de comunicación digital. A continuación se establece una clasificación del impreso en categorías conforme a la capacidad de interacción que permiten y se analizan diversos ejemplos para cada una de ellas. A tal fin se estudian diversas composiciones editoriales, elegidas por su relevancia como instrumentos esenciales de interacción gráfica. Se observa de qué forma los recursos meramente gráficos (tipografía, color, tamaño y posición) desempeñan un papel en este proceso y cómo las relaciones compositivas son importantes en la comunicación del sentido.

\subsection{Modelos para la interacción impresa}

Según su contenido textual e icónico un documento se organizará en el soporte impreso conforme a un determinado modelo para la interacción que tendrá que ver con sus objetivos comunicativos. El lenguaje gráfico mediante la tipografía, el color, la posición y el tamaño, comunica al lector la importancia de cada apartado para guiar la lectura de todo el conjunto en un sentido determinado.

El criterio seguido para seleccionar los ejemplos incluidos en este trabajo guarda relación con la capacidad interactiva que cada uno de ellos proporciona al lector. Para determinar qué tipos de organización son posibles, es necesario, en primer lugar, describir los componentes de la página que son los siguientes:

1. Elementos de contenido textual. El texto principal y, cuando lo hay, el texto complementario, las notas a pie de página y los pies para fotografías,

DOI: ri14.v12i1.655 | ISSN: 1697-8293 | Año 2014 Volumen 12 Nº 1 | ICONO14 
ilustraciones y otros elementos gráficos. La organización jerárquica de lo expresado se hace visible mediante la aplicación de las normas ortotipográficas que determinan el uso de las diversas variantes de cada letra: cursivas, negritas, etc.

2. Elementos de contenido icónico: fotografías, dibujos, diagramas y gráficos. El tamaño, la posición y el encuadre son los factores principales que proporcionan la necesaria relevancia gráfica a estos componentes.

3. Elementos de continuidad que confieren unidad a todo el documento y facilitan el acceso a cada una sus partes. El encabezamiento, el formato y los folios son los principales instrumentos para la unidad gráfica. Por ejemplo, la retícula no sólo sirve para organizar el contenido; es también un instrumento para homogeneizar gráficamente las páginas.

4. Elementos para la organización estructural, necesarios para la distribución de los contenidos. Son diversos los autores que han querido hacer una clasificación de este elemento gráfico en función de sus posibilidades. (MüllerBrockmann, 1960. Samara, 2007. Haslam, 2007) Pero en los especialistas prevalece una idea que debería ser discutida: la convicción de que cada disposición reticular se corresponde con un determinado tipo de organización de los contenidos y, en consecuencia, con una distinta interacción. En síntesis, puede establecerse la existencia de tres tipos de organización:

- Retícula de manuscrito, con un único canal dispuesto linealmente.

- Retícula de columnas, que permite canales paralelos.

- Retícula modular, que puede tener en muchas una organización jerárquica.

5. Normas combinatorias. Criterios para combinar los contenidos y los elementos de continuidad en las diversas formas de retícula. Estas diversas formas de combinación pueden proporcionar un orden diferente en la organización del libro. Este orden puede ser:

- Sucesivo, donde la convivencia de texto e imágenes sólo es posible cuando 
se sitúan uno detrás de otro.

- Simultáneo, que permite contemplar a un tiempo imágenes y texto sin establecer un orden.

Según la distinta relevancia que los elementos gráficos tienen en la disposición gráfica, se han establecido cinco categorías en la organización de la página:

- Disposición lineal simple

- Disposición lineal jerárquica

- Disposición lineal icónica

- Disposición lineal interactiva

- Disposición gráfico plástica

\section{Resultados}

Se analizan a continuación los modelos de organización gráfica de la página impresa. Los ejemplos analizados son los siguientes:

1. La lluvia amarilla. Edición de Seix Barral para la colección Booket. 1997.

2. Después del Reich. Edición del Círculo de Lectores, Galaxia Gütenberg. 2010.

3. Ways of Seeing. Edición de Penguin, 1972. Diseñado por Richard Hollis.

4. Diccionario de Español Inglés, English Spanish. Edición de Espasa Calpe. 2001. Diseñado por Joaquín Gallego.

5. Freud. Sein Leben in Bildern un Texten. Edición para Insel Taschenbuch, 1989. Diseñado por Willy Fleckhaus para la edición original de 1974.

\subsection{Disposición lineal simple}

A partir de una retícula de manuscrito, formada por una única columna, y con tan sólo el folio, el texto discurre de manera lineal una página tras otras. Hay un solo tipo de párrafo, sin encabezamientos, y un limitado repertorio tipográfico. En 
la mayoría de los casos, se utiliza una sola escritura, tanto para el contenido como para los elementos de continuidad.

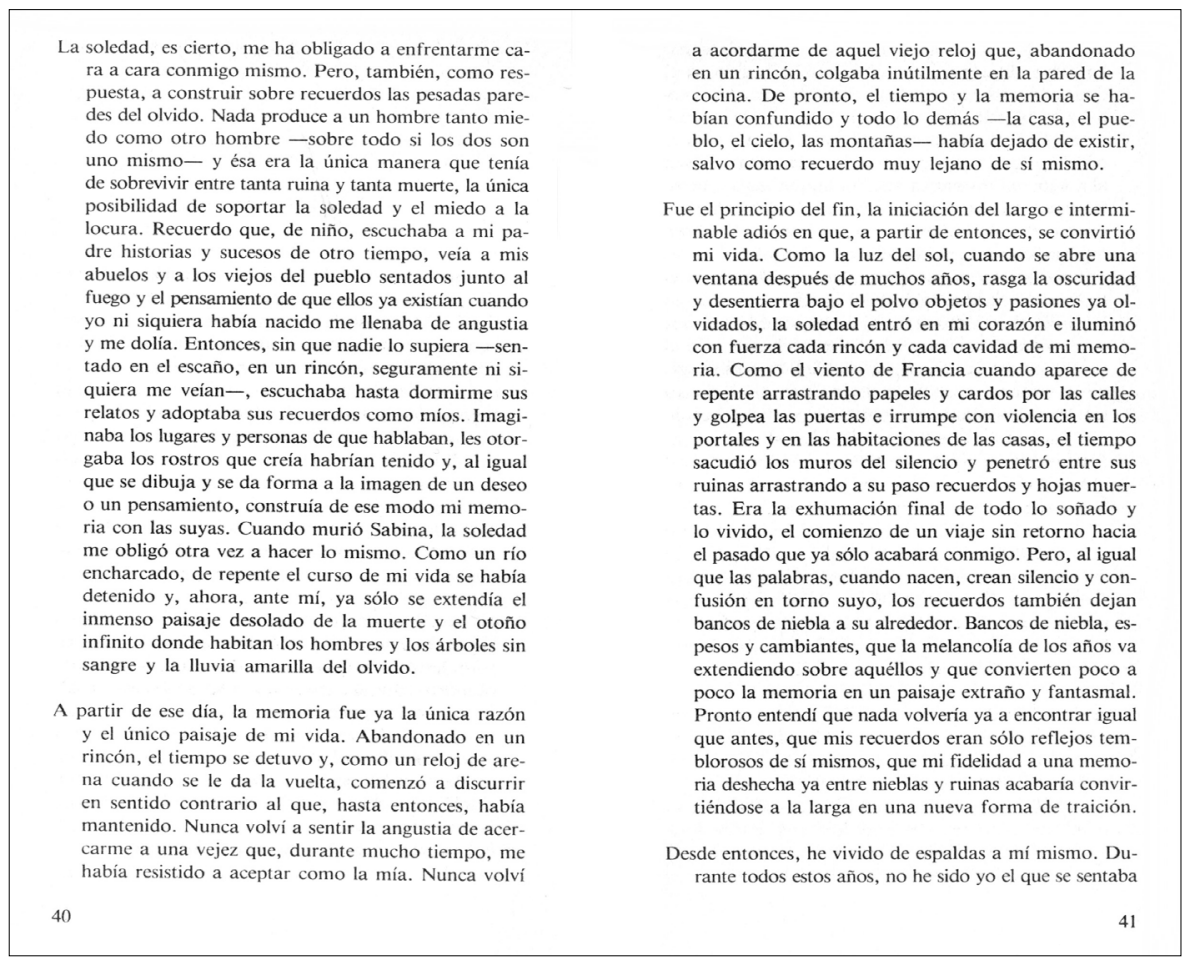

Imagen 1. Julio Llamazares. La lluvia amarilla. Seix Barral Booket, Barcelona, 1997. $180 \times 113$ milimetros aproximadamente. Diseño: No consta.

Como ejemplo se ha elegido un libro en formato de bolsillo de una novela convencional. En esta edición para Booket de la novela "La lluvia amarilla" puede apreciarse la disposición lineal del texto en la que nada pueda interrumpir su discurso. Destacan los párrafos en sangría francesa, solución inusual en una narración, único detalle que rompe la monotonía de las páginas pero que no afecta a la consideración "acompositiva" de su diseño.

En la disposición lineal es dominante la presencia de un flujo de texto que no puede ser leído en otro orden que no sea de principio a fin. Una novela, particularmente, si es breve no tiene otra alternativa; sin leer las primeras páginas, será difícil comprender las siguientes. Por supuesto, el lector puede hacer caso omiso 
de esta disposición y leer fragmentos sin orden ni concierto. El resultado, por muy atractivo que resultara, no guardaría relación con el sentido original del texto.

Este principio, presente en los cuadernos manuscritos y en los informes mecanografiados, dominado por la simetría y la sencillez, nació con la propia escritura. $\mathrm{Al}$ escribir, las palabras se disponen una detrás de otra, sin mayores artificios, en una masa simétrica y homogénea. La simetría clásica no sólo está presente en la página impresa, es predominante en la arquitectura y en otras formas de expresión; su vigencia queda ligada a la preferencia cultural por las tradiciones del pasado.

La tipografía actúa como un agente invisible. La distribución del texto se presenta como algo convencionalizado en una estructura, en cierto sentido, anticompositiva, que elude todo compromiso plástico (Tschichold, 1987). La composición clásica, se convierte, en palabras de Morison (1936) en "el medio eficaz al servicio de un fin esencialmente utilitario y sólo accidentalmente estético" en la que la monotonía formal contribuye a centrar la atención del lector en lo exclusivamente literario. Dependerá la atención del sentido de las palabras, no de su forma ni de su posición.

\subsection{Disposición lineal jerárquica}

Como en el caso anterior esta disposición utiliza una retícula de manuscrito, es decir, con una sola columna, pero incluye más niveles de información (texto principal, notas, pies de fotografía) que tienen su correspondencia con las soluciones tipográficas adoptadas. El encabezamiento proporciona también una continuidad más matizada porque informa del título del libro y de los títulos de cada uno de los capítulos.

En la doble página aquí seleccionada, se diferencias tres niveles de información mediante soluciones tipográficas distintas en cuerpo e interlínea, pero similares en su intensidad. La posición de la nota en el pie de página y la ubicación bajo la fotografía de un texto explicativo contribuyen a reconocer la función de cada variante tipográfica con mayor exactitud.

DOI: ri14.v12i1.655 | ISSN: 1697-8293 | Año 2014 Volumen 12 Nº 1 | ICONO14 


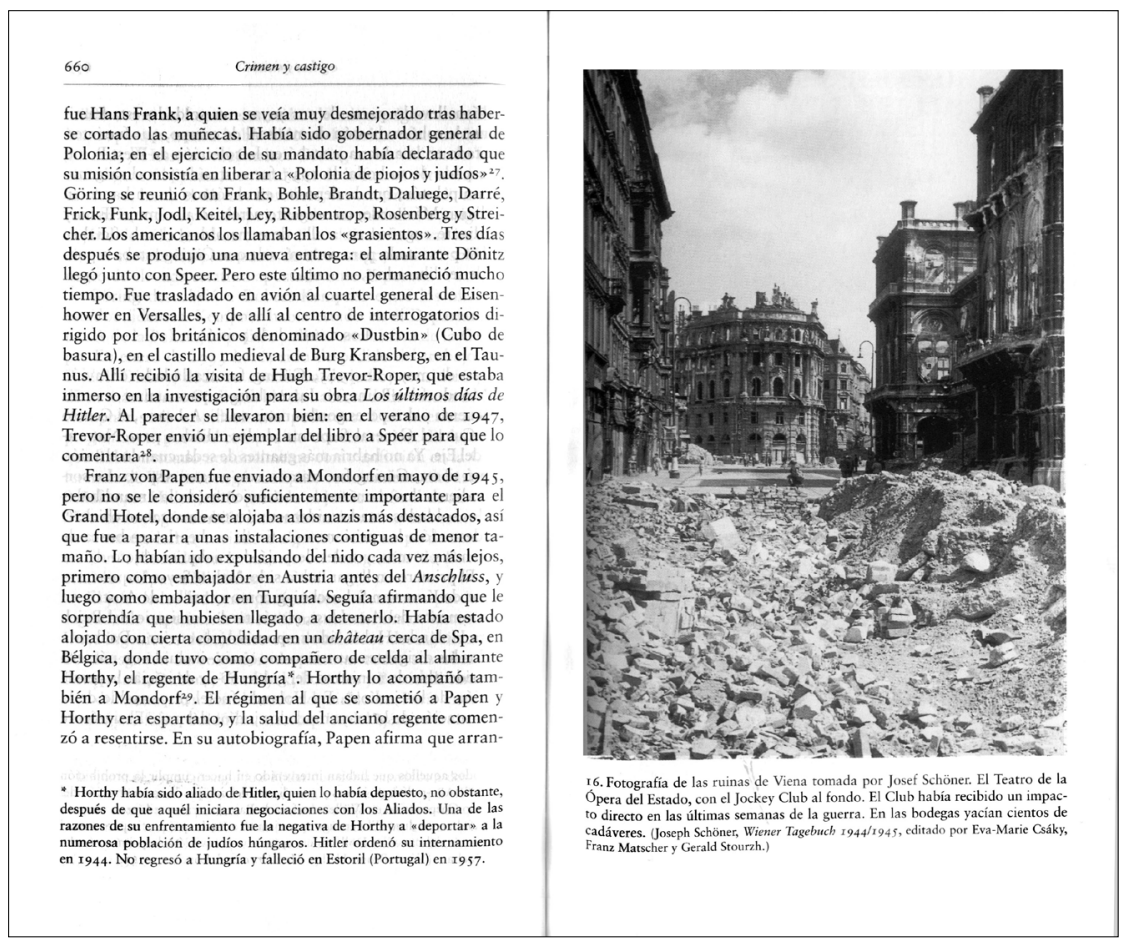

vImagen 2. Giles Macdonogh. Después del Reich. Crimen y castigo en la posguerra alemana. Círculo de Lectores, Galaxia Gütenberg. Barcelona,

2010. 223 × 145 milimetros aproximadamente. Diseño: No consta.

La disposición lineal sigue siendo la principal propuesta de lectura pero existen diversas alternativas en función de la profundidad con que el lector afronte el contenido y que derivaran en una percepción activa. En el ejemplo aquí observado, un libro académico constituido por texto principal y notas que conviven junto a fotografías, mapas y gráficos con sus correspondientes pies. Un soporte de estas características, como otras formas de concepción compleja, es concebido para ser leído a varios niveles no excluyentes en una interacción que deja al usuario un amplio margen de libertad. Notas e imágenes funcionan a modo de hipervínculos. Una opción de lectura puede obviar las notas y atender sólo al texto principal, pero puede detenerse para ver las imágenes y leer los textos explicativos. En un libro así el lector mira las fotografías en el orden que desea y, como suele ser relativamente extenso, es posible que comience leyendo los capítulos en orden distinto al inicialmente dispuesto. 


\subsection{Disposición lineal icónica}

La forma más sencilla de integrar imágenes es situarlas ordenadamente de forma lineal, interrumpiendo el transcurso de los párrafos de forma que los dibujos, fotografías o gráficos aparezcan junto a los textos en que son citados. Esta disposición fue muy frecuente hasta que las retículas modulares proporcionaron sistemas más complejos y flexibles. Pero frente a la retícula que supone una disposición apoyada en las cualidades gráfico plásticas de los elementos, la disposición lineal icónica permite un mayor control de la interacción porque no deja al lector otra opción para mirar las imágenes que en el orden en que han sido dispuestas. Cierto es que la mirada puede deambular por el impreso, pero las imágenes carecen de pies, por lo que su sentido es más claro si se respeta el orden lineal al que conduce todo el diseño.

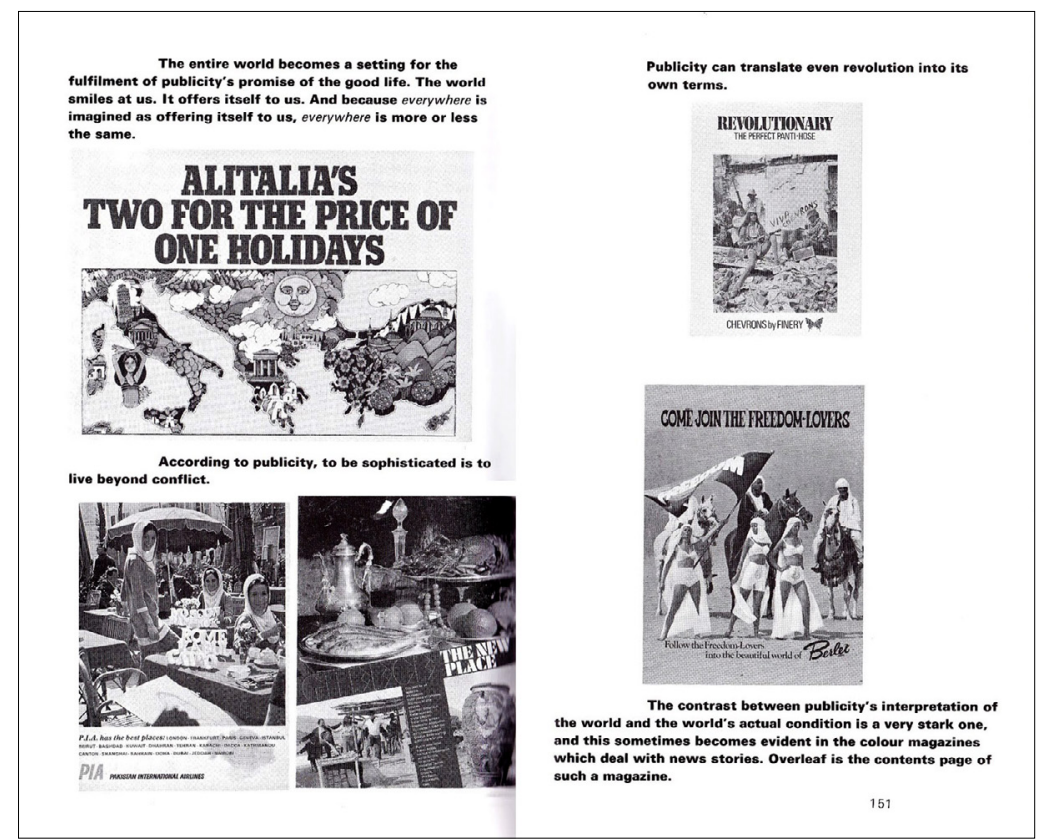

Imagen 3. John Berger. Ways of Seeing. Penguin. Harmondsworth, 1972. Diseño: Richard Hollis.

"Ways of Seeing" fue publicado a partir de la serie de televisión que la BBC emitiera a principios de los años setenta con textos de John Berger. Al reducir la interactividad, Richard Hollis reforzaba el propósito pedagógico del libro limitando

DOI: ri14.v12i1.655 | ISSN: 1697-8293 | Año 2014 Volumen 12 Nº 1 | ICONO14 
las posibles combinaciones perceptivas entre texto e imagen con la intención de mantener la narración lineal de la emisión televisiva.

En conversación con Emily King (Étapes, 2012) Richard Hollis explicaba el proceso que supuso la maquetación del libro. Al intercalar las imágenes en el texto, de forma sucesiva, sin utilizar una retícula modular, quiso mantener todo lo posible del original audiovisual. Había tomado esta idea del cineasta Chris Marker que, años antes, había publicado un libro con este modelo de organización para mantener el tipo de interacción de su obra audiovisual (Wilson, 2006). Esta simple sucesión de textos e imágenes recordaba también al libro Deutschland uber Alles que diseñara John Hertfield en los años treinta.

La disposición lineal icónica descuida los ajustes que caracterizan al diseño reticular. Los blancos en el impreso no son intencionados, no son módulos intencionados, sino la mera consecuencia del vacío que dejan las imágenes cuando se suceden unas a otras.

\subsection{Disposición lineal interactiva}

La existencia de más de una columna no contradice el principio lineal presente en este modelo de organización.

Pero lo que caracteriza este modelo es que no se apoya en la composición. Dividir la página en dos columnas no tiene otro objetivo que aprovechar el espacio, cada cosa se sitúa detrás de la anterior. Es el contenido el que orienta el orden de lo leído. El texto presenta un aspecto lineal o poco complejo que sin embargo carece de orden alguno que oriente la lectura.

Guías telefónicas, diccionarios, enciclopedias, anuarios, libros de consulta, directorios y otros productos afines son ejemplos de libros plenamente interactivos a pesar de su aparente disposición lineal. El diseño impreso es entendido como un interfaz de usuario (Bjarnason, 2012). Aunque las páginas están, obviamente, unas detrás de otras, no han de leerse en ese orden. No es que se anime al lector a decidir su propio recorrido, es que si no lo hace, la lectura carecería de sentido.

ICONO14 | Año 2014 Volumen $12 N^{\circ} 1$ | ISSN: 1697-8293 | DOI: ri14.v12i1.655 


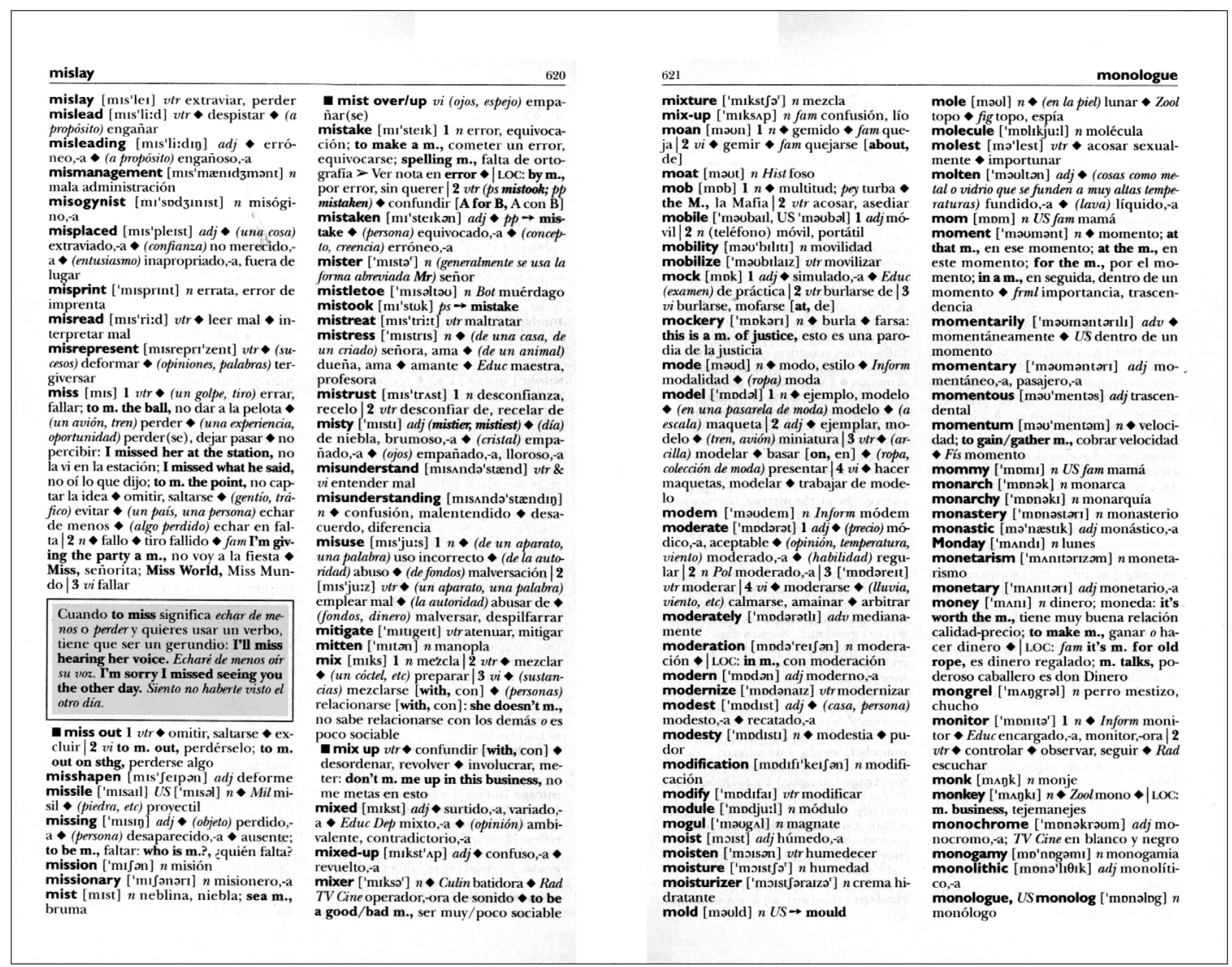

Imagen 4. Varios autores. Diccionario de Español Inglés, English Spanish. Espasa Calpe.

Madrid, 2001. 175 x 113 milimetros, aproximadamente. Diseño: Joaquín Gallego.

Es absurdo comenzar un diccionario por el principio, se trata de un contenido indexado, concebido para la percepción no lineal que dispone de un procedimiento de búsqueda, generalmente el orden alfabético y que asocia contenidos mediante referencias cruzadas. No será fácil que dos lectores sigan el mismo camino, ni siquiera que uno de ellos repita una misma trayectoria.

En el ejemplo aquí comentado pueden apreciarse rasgos de una disposición lineal donde un tratamiento tipográfico muy normalizado evita cualquier confusión sobre la importancia de cada apartado al establecer una clara jerarquía. Pero debe insistirse en que no existen relaciones espaciales entre las partes, más allá de las interrupciones que el espaciado produce en el flujo de texto. 


\subsection{Disposición gráfico plástica}

Esta disposición hace uso de una retícula modular en la que incluye imágenes de variado tamaño y encuadre. No existe jerarquía en los capítulos formados principalmente por imágenes. Pueden leerse de forma desordenada, a modo de un álbum de fotografías con anotaciones. Aunque existe un orden basado en la dirección de lectura para quien desee una sucesión cronológica de los documentos.

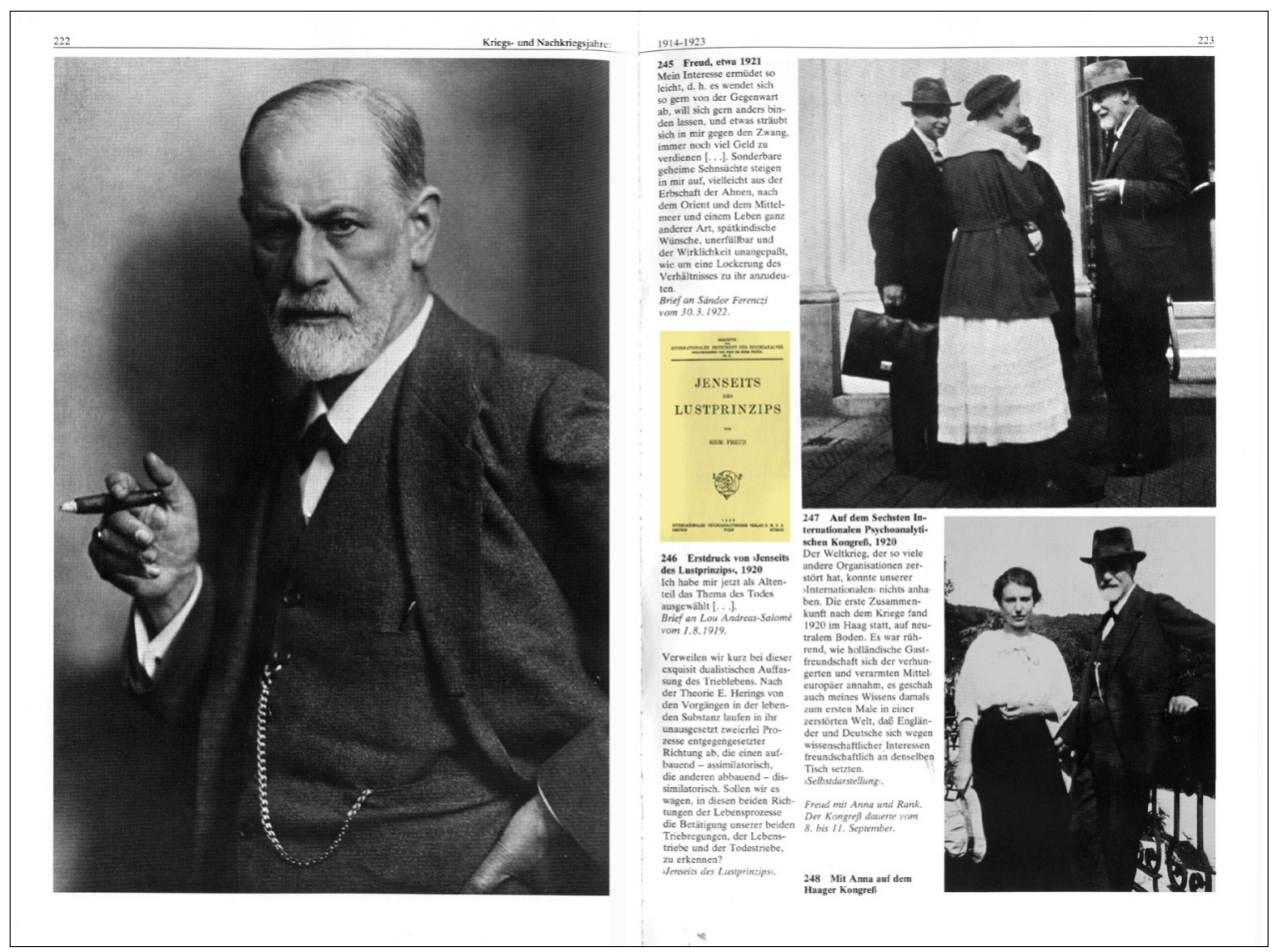

Imagen 5. Freud. Sein Leben in Bildern un Texten. Insel Taschenbuch. Frankfurt del Meno, 1989. $210 \times 140$ milímetros aproximadamente. Diseño: Willy Fleckhaus para la edición original de 1974.

Cuatro columnas combinadas con flexibilidad. En las páginas iniciales se utilizan tres columnas para el texto principal, dejando vacía la columna del margen. Encabezamientos. Los pies de imágenes se convierten en el texto principal en la parte más importante del libro. 
En un sistema de organización gráfico plástica, los contenidos se sitúan intencionadamente en un lugar concreto de la doble página para señalar la importancia de cada apartado y propiciar una mejor comprensión. La doble página como entidad de composición gráfica, no fue aceptada hasta finales del siglo XIX, pero resulto esencial para dotar al impreso de la necesaria condición de soporte compositivo que necesitaban las vanguardias. (Meggs, 1993)

Esta variante surgió como reacción al agotado uso de la disposición clásica. Los movimientos de vanguardia utilizaron la composición pictórica con textos como un recurso expresivo más. La asimilación de los principios de las vanguardias modificaron las proporciones tradicionales en favor de una distribución más compleja de los espacios y exploraron la capacidad del soporte para crear nuevas organizaciones visuales. La doble página tiene mucho que ver con el libro ilustrado. La complejidad de estos componentes hizo necesaria una retícula que proporcionara una cierta linealidad en la medida que señalase algún tipo de orden. En todo caso, la relevancia visual de los elementos gráficos depende de su forma, su dimensión, su color, y muy especialmente de su posición absoluta y relativa (West, 1993). El diseñador ubicaba cada elemento en aquel lugar que le correspondía por su importancia y le asignaba una característica formal adecuada a la relevancia concedida. Las revistas ilustradas establecieron este modelo compositivo para integrar textos con imágenes de diverso tamaño. Los libros de texto, con más o menos acierto, recurrían a este tipo de composición para hacer más fácil el aprendizaje. La memoria se apoyaba en la posición de cada parte y en la relación entre todas ellas: la diversidad de tratamientos tipográficos materializa la importancia relativa de cada texto.

Este libro, diseñado por Willy Fleckhaus originalmente en un tamaño de 29 x 20 centímetros, muestra su inclinación por el contraste, muy habitual en las soluciones gráficas del diseñador alemán. La composición reticular donde la posición y la disposición tipográfica ordenan los contenidos es ocultada mediante la disposición de fotografías con tamaños muy diversos. Imágenes y textos se presentan al lector sin orden establecido, permitiendo múltiples recorridos de la mirada por la página, recorridos visuales que asignan a cada componente la relevancia adquirida en esa lectura.

DOI: ril4.v12i1.655 | ISSN: 1697-8293 | Año 2014 Volumen 12 № 1 | ICONO14 


\section{Discusión y conclusiones}

En aquellas disposiciones lineales simples que apenas permiten interacción, la tipografía y el espacio blanco son los únicos elementos gráficos que organizan el contenido; y lo hacen en un orden que no puede ser otro que la sucesión de párrafos. Sólo la modificación de la letra puede hacer posible la expresión de la jerarquía. Este escaso repertorio limita las opciones de lectura pero garantiza al autor que su obra será leída en un sentido correcto. Por razones técnicas, la disposición lineal simple es la única que esta presente en condiciones razonables en los nuevos medios: en los libros electrónicos y en otros dispositivos similares. El texto constituido en un flujo continuo puede mostrarse en cualquier soporte porque no requiere de la posición sobre la página para su eficacia comunicativa.

En un nivel superior de complejidad, las composiciones lineales jerárquicas usan negritas, cursivas y cualquier otra variante tipográfica para resolver la imposibilidad de confiar a la posición funciones relevantes en un documento que precisa notas, pies para imágenes o índices onomásticos.

Es la inclusión de imágenes la que hace necesaria la búsqueda de formas alternativas de composición. Su variado tamaño, forma y contenido determinan una relación más complicada con el texto. De esta forma, la disposición lineal icónica se convierte en la forma más sencilla de integración de imágenes, la única que de forma efectiva aparece en los libros electrónicos por su sencillez. Aunque impide la interacción simultánea, respeta la intención del autor y evita lecturas no deseadas y es la más sencilla traducción al impreso de los contenidos originalmente audiovisuales.

Pero no proporciona una integración absoluta con el texto porque el espacio blanco adquiere un protagonismo excesivo y contribuye a establecer relaciones espaciales que en ocasiones contradicen la relevancia de los contenidos. Para resolver visualmente estos problemas, que son antes que nada problemas estéticos, las retículas modulares proporcionaron herramientas eficaces para el ajuste del espacio blanco. Consiguieron que el espacio vacío ocupara secciones de módulos y, al integrarse en el complicado entramado compositivo que formaban texto e imágenes, proporcionaron una mayor coherencia gráfica a la página impresa.

ICONO14 | Año 2014 Volumen $12 N^{\circ} 1$ | ISSN: 1697-8293 | DOI: ri14.v12i1.655 
Pero estos modelos de organización que tienen en la plástica su origen, no han proporcionado una ventaja evidente en la interacción gráfica. Las retículas modulares facilitan formas de composición más atrevidas, visualmente más innovadoras, pero complican la tarea del lector para conocer el orden idóneo. La retícula es un instrumento para combinar de manera armoniosa elementos gráficos muy dispares.

La interacción más compleja no está unida a las soluciones gráficas más elaboradas. Diccionarios y demás obras de consulta, utilizan disposiciones simples porque la interacción en estos casos no es realmente visual. La interacción se produce directamente con el contenido, al margen de la disposición gráfica. El lector busca palabras que se han dispuesto, unas detrás de otras, conforme a un orden alfabético de naturaleza no visual. No importa el tipo de letra o el color con el que se haya compuesto. La disposición gráfica es irrelevante para la decisión de leer o no leer, para buscar una palabra u otra.

La elección de las variantes tipográficas y la composición de las líneas no son más que una forma de hacer más legible el texto, de facilitar el acceso a los términos. La disposición lineal interactiva del papel impreso no proporciona a esos documentos las ventajas que tienen en los soportes electrónicos. Un diccionario, una guía de datos en su versión digital es infinitamente más interactiva que su equivalente impreso porque proporciona procedimientos de búsqueda y sistemas de relaciones más complejos. Pero esa clara ventaja que se manifiesta en los procedimientos de búsqueda, no tiene que ver con la complejidad de la composición.

\section{Referencias}

Arroyo Almaraz, I. y Baños González, M. (2013) Tendencias de la comunicación del tercer sector en la web 2.0: Análisis retórico de los tropos. Icono 14. Vol. 11. $n^{\circ}$ 2. pp. 331-356.

Baines, P. (2005) Penguin by Design. Londres: Allan Lane.

Bjarnason, B. Hierarchies of ebook Design. 20 de marzo de 2012, en http://www. baldurbjarnason.com/notes/hierarchies-of-ebook-design/ 
Blackwell, L. (1992) Twentieth Century Type. Londres: Laurence King.

Burke, C. (2007) Active literature. Jan Tschichold and New Typography. Londres:

Hyphen Press.

Castells, M. (2001) La galaxia Internet. Barcelona: Areté.

Dans, E. (2010) Todo va a cambiar. Barcelona: Deusto.

Drucker, J. (2009) Philip Meggs and Richard Hollis. Design Culture. Vol. 1. n ${ }^{0}$ 1. pp. 51-78.

Eco, U. (1993) Lector in fábula. La cooperación interpretativa en el texto narrative.

Barcelona: Lumen.

Gamonal, R. (2011) Retórica aplicada a la enseñanza del diseño gráfico. Icono 14.

Vol. 9. $n^{0}$ 3. pp. 426-438.

King, E. (2012) Richard Hollis. Étapes. $n^{0}$ 206. p. 30-37.

Kinross, R. (1992) Modern Typography: an Essay in Critical History. Londres:

Hyphen Press.

Marín Álvarez, R. (2013) Ortotipografía para diseñadores. Barcelona: Gustavo Gili. Martínez de Sousa, J. (1994) Manual de edición y autoedición. Madrid: Pirámide. McLean, R. (1975) Jan Tschichold: typographer. Boston: David R. Godine Publisher. Moggridge, B. (2010) Designing Media. Camdbridge: MIT Press.

Morison, S, (1936) First Principles of Typography. Nueva York: Yale University Press. Norman, D. (2005) El diseño emocional. Barcelona: Paidós.

Müller Brockmann, J. (1960) Rastersysteme für die visuelle Gestaltung. Zúrich: Niggli.

Rinker, D. (2007) Ulm School of Design, 1953-1968. Ulm: Hfg Archiv /Ulmer Museum.

Samara, T. (2004) Diseñar con o sin retícula. Barcelona: Gustavo Gili.

Spiekermann, E. (1993)Stop, Stealing Sheeps, and Find Out how Type Works.

Mountain View: Adobe.

Spitz, R. (2012) HfG IUP IFG. Ulm 1968 -2008. Ulm: Stiftung Hochschule für Gestaltung HfG Ulm.

Tschichold, J. (1987) Die neue Typogaphie. Berlín: Brinkmann und Bose Verlag. Tschichold, J. (1949) Was jedermann vom Buchdruck wissen sollte. Basilea:

Birkhäuser Verlag.

Veblen, T. (2004) Teoría de la clase ociosa. México DF: Fondo de Cultura Económica. Wilson, C. (2006) Reputations: Richard Hollis. Eye Magazine. nº 59. Vol. 15. 